\title{
Ergenlerde Mutluluk Durumu, İyilik Hali, Kendini İfade Edebilme ve Sosyal Medya Bağımlılığının İlişkisi
}

\section{The Relationship of Happiness, Well-being, Self-Expression and Social Media Addiction in Adolescents}

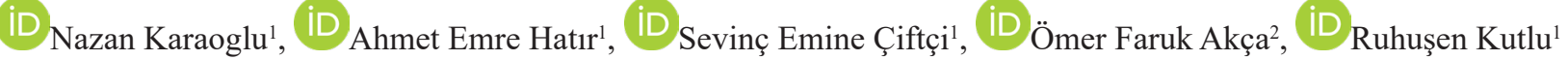

${ }^{1}$ Necmettin Erbakan Üniversitesi, Meram Tıp Fakültesi, Aile Hekimliği AD, Konya, Türkiye

${ }^{2}$ Necmettin Erbakan Üniversitesi, Meram Tıp Fakültesi, Çocuk ve Ergen Ruh Sağlı̆̆ı ve Hastalıkları AD, Konya, Türkiye

$\ddot{O z}$

Amaç: Bu çalışmanın amacı psikososyal ve bedensel etkileriyle özel bir sürę̧ olan ergenlik dönemindeki iyilik hali, mutlu olma, kendini ifade etme ile sosyal medya bağımlılığının ilişkisin araştırmaktır.

Gereç ve yöntem: Tanımlayıcı, kesitsel araștırmada, akranları aracılığıyla ulaşılan 11-18 yaş arası 384 ergen, gönüllülük temelinde demografik bilgi formu, Engagement, Perseverance, Optimism, Connectedness, Happiness (EPOCH) Ölçeği, Duyguları İfade Etme Ölçeği (DİEÖ), Oxford Mutluluk Ölçeği-Kısa Formu (OMÖ-KF) ve Sosyal Medya Bağımlılığı Ölçeği-Kısa Formunu (SMBÖKF) yanıtlamıștır.

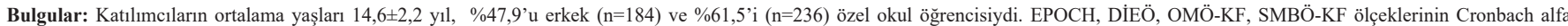
değerleri sırasıyla $0,818,0,648,0,770$ ve 0,810 bulundu. Kendisini başarısız görenlerin ( $\% 24,7 ; \mathrm{n}=95)$ EPOCH, OMÖ-KF, Di̇EÖ puanları ( $76,2 \pm 16,9 ; 21,7 \pm 5,9 ; 67,7 \pm 12,9)$ başarılı görenlerden $(87,9 \pm 14,2 ; 25,5 \pm 5,2 ; 71,1 \pm 11,2)$ düșüktü ( $\mathrm{p}=0,001 ; \mathrm{p}=0,001 ; \mathrm{p}=0,008)$. DİEÖ puanı kızlarda $(72,1 \pm 11,2)$ erkeklerden $(68,2 \pm 11,9)$ yüksek ( $\mathrm{p}=0,002)$, özel okulda okuyanların OMÖ-KF puanı $(25,5 \pm 5,4)$ devlet okulunda okuyanlardan $(22,9 \pm 5,6)$ farklıydı $(\mathrm{p}=0,001)$. SMBÖ-KF puanı devlet okulunda okuyanlarda $(3,2 \pm 2,9)$ özel okulda okuyanlardan $(2,5 \pm 2,3)$ ( $\mathrm{p}=0,033)$, kendini başarısız görenlerde $(3,8 \pm 2,8)$ bașarılı görenlerden $(2,4 \pm 2,5)(\mathrm{p}=0,001)$ ve spor yapmayanlarda $(3,0 \pm 2,7)$ spor yapanlardan $(2,4 \pm 2,5)$ fazlaydı $(\mathrm{p}=0,035)$. EPOCH puanı spor yapanlarda $(87,2 \pm 15,8)$ spor yapmayanlardan $(83,9 \pm 15,6)$ yüksekti $(\mathrm{p}=0,038)$. Katılımcıların EPOCH ile SMBÖ-KF puanı arasında negatif yönde zayıf $(\mathrm{r}=-0,199, \mathrm{p}=0,001)$, OMÖ ile SMBÖ-KF puanı arasında ise negatif yönde orta düzeyde korelasyon saptandı $(\mathrm{r}=-0,260, \mathrm{p}=0,001)$.

Sonuç: Özel okulda okuyan ergenlerin devlet okulunda okuyanlara göre daha mutlu ve daha az sosyal medya bağımlısı olması, kendini başarılı görenlerin kendini daha iyi ifade etmesi, daha mutlu olması, kendini başarısız görenlerde, devlet okullarında okuyanlarda ve spor yapmayanlarda sosyal medya bağımlılığının daha yüksek olması dikkat çekicidir. Bu sonuçlar ergenlik döneminde sosyal teșviklerin, spora yönlendirmenin ve genel iyi oluşlarını artırabilmek için psikolojik ve ekonomik desteklerin önemini ortaya koymaktadır.

Anahtar kelimeler: Ergenlik, sosyal medya, duyguları ifade etme, mutluluk

Abstract

Objective: The aim of this study is to investigate the relationship between well-being, being happy, self-expression and social media addiction of adolescence which is a special period with its psychosocial and physical effects.

Material and methods: In descriptive, cross-sectional research, 384 adolescents aged 11-18, reached by their peers answered voluntarily, demographic information form Engagement, Perseverance, Optimism, Connectedness, Happiness (EPOCH) Scale, Emotional Expression Scale (EES), Oxford Happiness Scale-Short Form (OHS-SF) and Social Media Addiction Scale- Short Form (SMAS$\mathrm{SF})$.

Results: The mean age of the participants was $14.6 \pm 2.2$ years, $47.9 \%$ were male $(\mathrm{n}=184)$ and $61.5 \%(\mathrm{n}=236)$ were private school students. Cronbach alpha values of EPOCH, EES, OHS-SF, SMAS-SF scales were found $0.88,0.6648,0.770$ and 0.810 , respectively. EPOCH, OHS-SF, EES scores $(76.2 \pm 16.9 ; 21.7 \pm 5.9 ; 67.7 \pm 12.9)$ of those who consider themselves unsuccessful $(24.7 \%$; $\mathrm{n}=95)(87.9 \pm 14.2 ; 25.5 \pm 5.2 ; 71.1 \pm 11.2)$ were low $(\mathrm{p}=0.001 ; \mathrm{p}=0.001 ; \mathrm{p}=0.008)$. EES score is higher in girls $(72.1 \pm 11.2)$ than boys $(68.2 \pm 11.9)$ ( $\mathrm{p}=0.002)$, OHS-SF score of those studying in private school (25.5 \pm 5.4$)$ is in public school (22.9 \pm 5.6$)$ was different $(\mathrm{p}=0.001)$. The SMAS-SF score was higher in public school students $(3.2 \pm 2.9)$, than private school students $(2.5 \pm 2.3)$ ( $\mathrm{p}=0.033)$, and

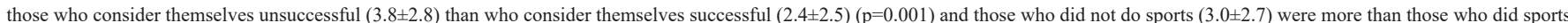
$(2.4 \pm 2.5)(\mathrm{p}=0.035)$. EPOC-H score was higher in those who do sports $(87.2 \pm 15.8)$ than those who do not $(83.9 \pm 15.6)(\mathrm{p}=0.038)$. There was a weak negative correlation $(\mathrm{r}=-0,199, \mathrm{p}=0.001)$ between the participants> EPOCH and SMAS-SF score, and a moderate correlation between the OHS-SF and SMAS score $(\mathrm{r}=-0,260, \mathrm{p}=0.001)$.

Conclusion: It is noteworthy that adolescents studying in private school are happier and less social media addicted than those who study in public school. It is also interesting that those who consider themselves successful express themselves better and are happier while those who consider themselves unsuccessful, public school students and those not making sports have higher social media addiction. These results show the importance of social support, guidance to sports and psychological and economic enforcement during adolescence period for their well being.

Key words: Adolescence, social media, expressed emotions, happiness

Bu çalıșma, 5. Uluslararası Sağlık Bilimleri ve Aile Hekimliği Kongresi İzmir, Türkiye, 2020’de sözlü olarak sunulmuştur.

Yazışma Adresi: Nazan Karaoğlu, Necmettin Erbakan Üniversitesi Meram Tıp Fakültesi, Yeni Hastane Binası, Aile Hekimliği Anabilim Dalı, Konya

E-Posta: drnkaraoglu@gmail.com

Alınma Tarihi: 15.05.2020 / Kabul Tarihi: 24.09.2020 / Yayımlanma Tarihi: 20.09.2021

Ergenlerde İyilik Hali ve Sosyal Medya Bağımlılığı - Karaoğlu ve ark.

Genel Tip Derg 2021;31(3)208-215 
İyi bir yaşamın nasıl olması gerektiği ile ilgili tartışmalar iyi oluş kavramının ve hayata olan etkisinin tanımlanması gereğini doğurmuş ve "iyi oluş" kavramını konu alan bilimsel araştırmalara yol açmıştır (1-9). "İyi oluş" kavramının evrensel bir tanımı olmamakla birlikte çok sayıda model iyilik halini açıklamaya çalışmaktadır (2,3,57). Ryff'in 1989 'da ortaya attığ "psikolojik iyi oluş modeli" kendini kabul, olumlu ilişkiler, özerklik, çevresel hakimiyet, yaşam amaçları ve kişisel gelişim boyutlarından oluşmaktadır (6). Keyes ise 1998 'de iyiliği tanımlarken sosyal boyutların önemini vurgulamış ve bunların bireysel boyutlara eklenmesi gerektiğini söylemiştir (7). Ancak literatürdeki insan psikolojisi araştırmaları daha çok olumsuz duygulara odaklanmaktadır ve pozitif duygular üzerine yapılan araştırmaların eksikliği dikkat çekmektedir $(2,3)$. Bu olumlu duygulara yönelim sorunlarla uğraşmaktan çok kişinin güçlü yanlarını geliştirmeyi öncelikleyen araştırmaların artmasına neden olmuştur $(2,3,10)$. Ardından Seligman 2011 yllında Positive Emotions, Engagement, Relationships, Meaning, and Acomplishment (PERMA) modelini öne sürmüş ve iyilik kavramını beş maddeye dayandırmıştır (10). Bunlar bağl1lık, olumlu duygular, anlam, olumlu ilişkiler ve başarılardır. Ancak PERMA modeli yetişkinlere yöneliktir. Ergenlerde iyilik durumunu ölçmek yetişkinlere göre daha zordur çünkü ergenler henüz yeterli eğitim almamıştır, dikkatlerinin odağı farklıdır ve ölçek sorularına verdikleri yanıtlar henüz iyilik kavramı ve buna benzer soyut kavramlar tam olarak onlarda ifade bulmadığından bias yaratır. Ayrıca onay alma, kabul görme isteği nedeniyle hep doğru olduğunu tahmin ettiği seçeneği işaretleme eğilimleri vardır $(11,12)$. Bu nedenle Kern ve arkadaşları 2015'te PERMA modelini ergenlere uyarlamış ve ergenler için beş boyutlu iyi oluş modelini ortaya koymuşlardır. $\mathrm{Bu}$ modelde; bağl1lık, kararlılık, iyimserlik, ilişkililik ve mutluluk ölçütleri temel alınmış ve Engagement, Perseverance, Optimism, Connectedness, Happiness (EPOCH) modeli olarak adlandırılmıştır (3).

Zihinsel iyi oluş; bireyin duygusal, fiziksel ve sosyal refahıyla ayrılmaz bir şekilde bağlantılıdır ve zihinsel hastalığın olmamasından daha çok şeyi ifade eder (11). Bireylerin iyilik hali fiziksel sağlıklarından, ilişkilerinden ve yaşadıkları sosyal, ekonomik, kültürel, çevresel koşullardan etkilenmektedir. Zihinsel refah bir bireyin yaşam kalitesine etki etmekle kalmayıp tüm topluma olumlu yönde etki eder ayrıca psikolojik ve fiziksel sağlık gibi önemli yaşam olaylarıyla başa çıkma şeklini etkilediği düşünüldüğü için çocuklar ve gençler için özel bir öneme sahiptir $(11,13)$. Çocukluktan yetişkinliğe evrilme olarak bilinen ergenlik dönemi, psikoanalitik görüşe göre diğer dönemlere nazaran daha sorunlu ve zorlu bir dönem olarak bilinmektedir (14) $\mathrm{Bu}$ dönemde ergenler impulsif ve riskli davranışlar sergileyen bireyler olarak görülür ve bu irrasyonel ergen davranışları hormonal değişime bağlanabilmektedir (14). Bir türbülans olarak tanımlanan bu dönemde depresyon ve kaygı bozuklukları, madde kullanım bozuklukları ve en önemlisi intihar ve ölümler görülmektedir $(15,16)$ Ülkelere göre değişmekle birlikte pek çok ülkede ergenler önlenebilir ve tedavi edilebilir sebeplerle ölmüştür. Oysa bu dönemin kalıcı hasarlar oluşmadan geçirilmesi mümkündür (17). Örneğin; kendini ifade edemeyen ergenler yetişkinlik dönemlerinde de birçok sorunla karşılaşabilir. Son 20 yılda duyguları iyi ifade etmenin iyi oluşla ilişkisini araştıran birçok araştırma yapılmıştır. $\mathrm{Bu}$ çalışmalarda duyguların iyi bir şekilde ifade edilmesi akıl ve beden sağlığının önemli bir göstergesi olarak görülmektedir $(8,18)$.

Kendini çekinmeden, görünmeden ifade edebilmenin bir yolu olan sosyal medya ergenlerde daha fazla olmakla birlikte her yaş grubunun hayatında yer almaktadır. Ergenlerde sosyal medya kullanmanın sosyalleşme, okul derslerine yardımcı olma, sağlıkla ilgili konulara kolayca erişebilme gibi olumlu yönleri olduğu gibi sanal zorbalık, online taciz, gizlilik endişesi, facebook depresyonu, internet bağımlılı̆ğ gibi olumsuz yönleri üzerinde de özellikle durulmaktadır $(8,18,19)$. Ergenlik döneminin en önemli sorunlarından biri olan intihar davranışı; kendini iyi ifade edememe, taklit, özenme, depresyon ya da istismar sonucu gelişebilmektedir $(17,20)$.

Sonuç olarak özel ve önemli bir süreç olan ergenlik döneminde iyi olma, duygulanım yönü, kendini mutlu hissetme, duygularını ifade edebilme ve internet bağımlılı̆̆ 1 arasındaki bağın ortaya çıkarılması ergen nüfusa yönelik tehditlere karşı önlem alabilmek açısından önemlidir. Bu bağı ortaya çıkarabilmek için de araştırmaya ihtiyaç vardır ve ne yazık ki bu konuda yapılmış çalışma azdır. Bu çalışmanın amacı da psikososyal ve bedensel etkileriyle özel bir süreç olan ergenlik dönemindeki iyilik hali, mutlu olma, kendini ifade etme ile sosyal medya bağımlılığının ilişkisini araştırmaktır.

\section{Gereç ve Yöntem}

Tanımlayıcı ve kesitsel tipte olarak yapılan bu araştırmada \%5 hata pay1 \%95 güven aralığı ile en az 377 ergenin çalışmaya dahil edilmesi planlandı. Çalışma için alınan etik kurul onayından sonra, altı aylık bir süreçte değişik sosyal ağlar ile duyuru yapılarak çalışmanın amacı açıklanıp ebeveynlerin onay verdiği gönüllülerin verilen linkteki anket formunu doldurmaları istendi. Akranların akranlara iletimiyle veriler elde edildi. Açıklama kısmında akranlarına da linki iletmeleri yönündeki istekle hedeflenen kitleye ulaşıldı. Çalışmaya alınma için temel kriterler; 11- 18 yaş arasında olma ve çalışmaya katılmayı kabul etme ve anadilinin Türkçe olmasıydı.

\section{Verilerin Toplanması}

Katılımcılar için sosyodemografik bilgiler, Engagement, Perseverance, Optimism, Connectedness, Happiness (EPOCH) Ölçeği, Duyguları İfade Etme Ölçeği (DİEÖ), Oxford Mutluluk Ölçeği-Kısa Formu (OMÖ-KF) ve Sosyal Medya Bağımlılı̆̆ Ölçeği-Kısa Formunun (SMBÖ-KF) yer aldığı toplamda 67 sorudan oluşan bir anket Google forms üzerinden oluşturuldu. Anket 10 ergen üzerinde pilot olarak uygulandıktan sonra anketin anlaşılabilirliği, uygulanabilirliği hakkında sorun varsa düzeltildi ve bu toplanan veriler ana çalışmada kullanılmadı. Anket formunda toplam 67 soru için cevaplanma süresi pilot çalışmada yüzyüze uygulandığında 8-10 dakika, linkten ise 4-5 dakika olarak belirlendi. Bu durumun ergen yaş grubunun teknolojik aletlerde okuma ve işlem hızı nedeniyle olabileceği düşünüldü. Veri toplarken birbirini tanıan, aynı sinıfta okuyan, sosyal medyada aynı gruplara üye ergenlerin birbirlerine anket linkini iletmesi yolu izlendi. İlk ulaşılan ergenler araştırmacıların çocukları, yakınları aracıllğıyla ulaşılan ergenlerdi. Altı aylık süreç içinde ayda bir bu ergenler aracılığıyla link hatırlatmaları yapıldı ve aralıklı olarak sistemde biriken anket sayısına bakılarak altı ay sonunda veri toplama sonlandırıldı.

Çalışmada oluşturulan anket formunun içeriği aşağıdaki gibidir:

1- Demografik Bilgi Formu: Bilgi formu 15 sorudan oluşmaktadır. Formun içeriğinde katılımcının sınıfı, yaşı, cinsiyeti, gelir durumu, okuldaki başarı durumu, kaldığı yer ve kiminle kaldığı sorularıyla beraber yapılan literatür çalışmalarında uyku durumuna etkisi olduğu düşünülen faktörlerin sorgulandığı açık ve çoktan seçmeli sorular yer ald1.

Ergenlerde İyilik Hali ve Sosyal Medya Bağımlılığı - Karaoğlu ve ark. 
2- Engagement, Perseverance, Optimism, Connectedness, Happiness (EPOCH) Ölçeği:

Kern ve arkadaşları tarafindan geliştirilen EPOCH Ölçeği, Seligman'ın iyi oluş ile ilgili beş boyutlu kavramsallaştırmasını ölçmeyi amaçlamaktadır (3). Bu beş boyutlu iyi oluş modelinin ergenler için uyarlanması sonucunda bağl1lık (engagement), kararlılık (perseverance), iyimserlik (optimism), ilişkililik (connectedness) ve mutluluk (happiness) boyutları geliştirilmiştir. Bağlılık, kişinin kendisini bütünüyle yaptığ 1 işe vermesi, kararlılık, kişinin engellerle karşılaşsa bile hedeflerine ilerleme konusunda gösterdiği beceriyi, iyimserlik, gelecek yaşamdan umutlu olmayı, ilişkililik ise diğerleriyle ilişkilerinden memnun olmasını ifade eder $(2,3)$. Ölçeğin Türkçe geçerlik, güvenirliği Demirci ve Ekşi tarafından 2015 yılında yapılmıştır (1). Bağlılık 5,7,11,12. maddeler, kararlılık 2,9,17,19. maddeler, iyimserlik 3,13,15,18.maddeler, ilişkililik $1,10,14,16$. maddeler ve mutluluk $4,6,8$ ve 20 . maddeler ile ölçülmektedir. Ölçekteki maddeler 1 (hiçbir zaman) ile 5 (her zaman) arasında 5'li Likert ile puanlanmaktadır. Ölçeğin değerlendirilmesinde, her boyutta puanların ortalamasının alınmasiyla 1 ile 5 arasında bir puan üretilmekte ve bu 5 boyut gösterge paneli yaklaşımı ile rapor edilmektedir. Her boyutta 4 madde olmak üzere toplamda 20 madde bulunan ölçekte, ters puanlanan madde yoktur (1).

3)Duyguları İfade Etme Ölçeği (DİEÖ): King ve Emmons (1990) tarafından geliştirilen duyguları ifade etme ölçeği sözel ve sözel olmayan biçimde hem kişiler arası ilişkilerde, hem de kişiler arası ilişkilerden bağımsız olarak duyguları ne kadar ifade ettiğimizi ölçmek amacıyla geliştirilmiştir (21). Ölçeğin Türkçe geçerlik, güvenirliği Kuzucu tarafından 2011 yılında yapılmıştır (22). Toplam 16 maddeden oluşan ölçeğin maddeleri "olumlu" ve "olumsuz" ile "yakınlık" duygularının ne kadar ifade edildiğini değerlendiren maddelerden oluşmaktadır. Ölçekte yer alan 9, 13, 11, 4, 16, 3 ve 15. maddeler birinci faktör olan olumlu duygu ifadesinde, $6,12,1,7$ ve 8. maddeler ikinci faktör olan yakınlık duygu ifadesinde, 2, 5, 14 ve 10. maddeler ise üçüncü faktör olan olumsuz duygu ifadesinde yer almaktadır. Ölçek 7'li Likert tipte olup "kesinlikle katılmıyorum=1" ile "kesinlikle katıllyorum=7" puan alır. Ölçekte yer alan 6. ve 14. maddeler negatif maddeler olduğundan ters puanlanır. Toplam ölçek puanının artışı duyguların daha fazla ifade edilebildiği gösterir $(21,22)$.

3) Oxford Mutluluk Ölçeği-Kısa Formu (OMÖ-KF): Hills ve Argyle (2002) tarafından geliştirilen ölçeğin Türkçe formu yedi maddeden oluşmaktadır (4,23). Kendi kendine yanıtlanan OMÖ-KF beşli Likert tipi bir ölçektir. Hiç katılmıyorum=1, Tamamen katılıyorum=5 puan aldığı ölçekteki 1. ve 7. maddeler tersten puanlanmaktadır. Ölçekten alınan toplam puan arttıkça kişinin mutluluk düzeyi yükselir.

4) Sosyal Medya Bağımlılığı Ölçeği Kısa Formu (SMBÖ-KF): Van den Eijnden ve arkadaşları (2016) tarafından geliştirilmiştir (24). Ölçek The Diagnostic and Statistical Manual of Mental Disorders (DSM-5)'te araştırılacak, kesinleşmemiş tanılar bölümünde yer alan İnternet oyun bağımlılığ boyutlu olarak planlanmıştır. Ölçek 27 madde olarak geliştirilmiş daha sonra 9 maddelik kısa formu oluşturulmuştur. Ölçeğin Türkçe geçerlik, güvenirliği Taş tarafından 2017 yılında yapılmıştır (25). "Evet" ve "Hayır" şeklinde yanıtlanan ölçeğin puanlanması 0-9 puan şeklindedir ve kesme puanı 5 puandır. Yani 9 maddeden 5 ve üstü maddeye "Evet" diyenler sosyal medya bağımlısı kabul edilir $(24,25)$.

Ergenlerde İyilik Hali ve Sosyal Medya Bağımlılı̆̆ - Karaoğlu ve ark.

\section{Etik İzin ve İstatistik}

Araştırmanın etik izni çalışmaya başlamadan önce ............. Üniversitesi ....... Tıp Fakültesi İlaç ve Tıbbi Cihaz Dışı Araştırmalar Etik Kurul Başkanlığı'ndan 2018/1330 sayı numarası ile alınmıştır.

Google forms aracılığıyla elde edilen tüm veriler Statistical Package for the Social Sciences (SPSS) 22.0 istatistik bilgisayar programı ile analiz edildi. Normal dağılıma uygunluk Kolmogorov-Smirnov testi ile değerlendirildi. Veriler normal dağılmadığı için ikili gruplarda Mann-Whitney U testi, çoklu gruplarda Kruskal Wallis testi olmak üzere non- parametrik testler kullanıldı. Tanımlayıcı istatistikler say1, yüzde, ortalama ve standart sapma ile ifade edildi. Her ölçeğin güvenirlik puanları (Cronbach alfa) hesaplandı. Ölçekler arasındaki ilişkiyi belirlemek için öncelikle EPOCH, OMÖ, SMBÖ, DİEÖ parametrelerinin korelasyonları yapıldı. Daha sonra bunlardan korelasyonları önemli olanlar arasında lineer regresyon analizi yapıldı ve $p<0.05$ istatistiksel olarak anlamlı kabul edildi.

\section{Bulgular}

Altı aylık süreçte anket formunu eksiksiz olarak dolduran 384 ergenin \%47,9'u erkek ( $\mathrm{n}=184)$ olup ortalama yaşları 14,6 $\pm 2,2$ yıl idi. Yüzde 61,5'i (n=236) özel okul öğrencisiydi ve tüm grubun \% 75,3'ü $(\mathrm{n}=289)$ kendisini başarılı olarak görmekteydi. Tablo 1 katılımcıların demografik özelliklerini göstermektedir.

Tablo 1. Çalışmaya katılan ergenlerin demografik özellikleri

\begin{tabular}{|c|c|c|}
\hline & $\mathrm{N}$ & $\%$ \\
\hline Ergenler yaş & $\begin{array}{c}14,6 \pm 2,2 \\
(\text { Min:10, Maks:18) y1l }\end{array}$ & \\
\hline Anne yaş & $\begin{array}{c}42,4 \pm 5,5 \\
\text { (Min:30, Maks:60) yll }\end{array}$ & \\
\hline Baba yaş & $\begin{array}{c}46,0 \pm 5,7 \\
\text { (Min:32, Maks:60) yl }\end{array}$ & \\
\hline \multicolumn{3}{|l|}{ Cinsiyet } \\
\hline Kadın & 200 & 52,1 \\
\hline Erkek & 184 & 47,9 \\
\hline \multicolumn{3}{|l|}{ Aile gelir durumu } \\
\hline $0-2000 \mathrm{TL}$ & 30 & 7,8 \\
\hline $2000-4000 \mathrm{TL}$ & 89 & 23,2 \\
\hline $4000-6000 \mathrm{TL}$ & 107 & 27,9 \\
\hline $6000 \mathrm{TL}$ ve üzeri & 158 & 41,1 \\
\hline \multicolumn{3}{|c|}{ Ebeveynleri ile birliktelik durumu } \\
\hline Anne-baba birlikte & 359 & 93,5 \\
\hline Anne-baba ayri/ölmüşş & 25 & 6,5 \\
\hline \multicolumn{3}{|l|}{ İçinde büyüdüğü aile yapısı } \\
\hline Çekirdek aile & 327 & 85,2 \\
\hline Geniş aile & 57 & 14,8 \\
\hline \multicolumn{3}{|l|}{ Anne eğitim durumu } \\
\hline Lise ve alt1 eğitim & 179 & 46,6 \\
\hline Lise üstü eğitim & 205 & 53,4 \\
\hline \multicolumn{3}{|l|}{ Baba eğitim durumu } \\
\hline Lise ve alt1 eğitim & 116 & 30,2 \\
\hline Lise üstü eğitim & 268 & 69,8 \\
\hline \multicolumn{3}{|l|}{ Okuduğu okul } \\
\hline Özel okul & 236 & 61,5 \\
\hline Devlet okulu & 148 & 38,5 \\
\hline \multicolumn{3}{|l|}{ Okul başarısı algısı } \\
\hline Başarılı & 95 & 24,7 \\
\hline Başarısız & 289 & 75,3 \\
\hline \multicolumn{3}{|l|}{ Spor yapma durumu } \\
\hline Yapiyor & 133 & 34,6 \\
\hline Yapmiyor & 251 & 65,4 \\
\hline \multicolumn{3}{|l|}{ Arkadaş sayısı $(\mathrm{n}=285)$} \\
\hline 14 ve altında & 144 & 50,5 \\
\hline 14'ün üstünde & 141 & 49,5 \\
\hline \multicolumn{3}{|c|}{ Yakın arkadaş (kanka) sayısı $(\mathrm{n}=355)$} \\
\hline 3 ve altında & 185 & 52,1 \\
\hline 3'ün üstünde & 170 & 47,9 \\
\hline \multicolumn{3}{|c|}{ Arkadaşla geçirdiği süre (n=299) } \\
\hline 4 saat ve altı & 157 & 52,5 \\
\hline 4 saat üstü & 142 & 47,5 \\
\hline
\end{tabular}


EPOCH, DİE, OMÖ, SMBÖ ölçeklerinin Cronbach alfa değerleri sirasiyla $0,818,0,648,0,770$ ve 0,810 olarak hesapland1.

DİEÖ puanı kızlarda $(72,1 \pm 11,2)$ erkeklerden $(68,2 \pm 11,9)$ yüksek $(\mathrm{p}=0,002)$, özel okulda okuyanların OMÖ-KF puanı $(25,5 \pm 5,4)$ devlet okulunda okuyanlardan $(22,9 \pm 5,6)$ farklıydı $(\mathrm{p}=0,001)$. SMBÖKF puanı devlet okulunda okuyanlarda özel okulda okuyanlardan (3,2 $\pm 2,9-2,5 \pm 2,3 ; p=0,033)$, kendini başarısız görenlerde başarılı görenlerden $(3,8 \pm 2,8-2,4 \pm 2,5 ; \mathrm{p}=0,001)$ ve spor yapmayanlarda spor yapanlardan $(3,0 \pm 2,7-2,4 \pm 2,5 ; \mathrm{p}=0,035)$ fazlaydı. Kendisini başarısız görenlerin $(\% 24,7 ; n=95)$ EPOCH, OMÖ-KF, DİEÖ puanları $(76,2 \pm 16,9 ; 21,7 \pm 5,9 ; 67,7 \pm 12,9)$ başarılı görenlerden $(87,9 \pm 14,2$; $25,5 \pm 5,2 ; 71,1 \pm 11,2)$ düşüktü $(p=0,001 ; p=0,001 ; p=0,008)$. EPOCH puanı spor yapanlarda $(87,2 \pm 15,8)$ spor yapmayanlardan $(83,9 \pm 15,6)$ yüksekti ( $p=0,038)$. Tablo 2 EPOCH, DİEÖ, OMÖ-KF, SMBÖ$\mathrm{KF}$ ölçek puanlarının ergenlerin demografik özelliklerine göre karşılaştırmasını göstermektedir.

Tablo 2. EPOCH, DİEÖ, OMÖ-KF, SMBÖ-KF ölçekleri puanlarının demografik özellikler ile ilişkisi

\begin{tabular}{|c|c|c|c|c|}
\hline & $\begin{array}{l}\text { EPOCH } \\
\text { Ort } \pm \text { SD }\end{array}$ & $\begin{array}{l}\text { OMÖ-KF } \\
\text { Ort } \pm \text { SD }\end{array}$ & $\begin{array}{l}\text { SMBÖ-KF } \\
\text { Ort } \pm \text { SD }\end{array}$ & $\begin{array}{l}\text { DİEÖ } \\
\text { Ort } \pm \text { SD } \\
\end{array}$ \\
\hline \multicolumn{5}{|l|}{ Cinsiyet } \\
\hline Kadın & $85,3 \pm 16,5$ & $24,3 \pm 5,8$ & $2,9 \pm 2,6$ & $72,1 \pm 11,2$ \\
\hline Erkek & $84,8 \pm 14,9$ & $24,8 \pm 5,5$ & $2,6 \pm 2,7$ & $68,2 \pm 11,9$ \\
\hline 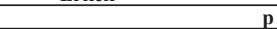 & 0,778 & 0,436 & 0,144 & 0,002 \\
\hline \multicolumn{5}{|l|}{ Aile gelir durumu } \\
\hline $0-2000 \mathrm{TL}$ & $85,6 \pm 15,8$ & $25,1 \pm 5,2$ & $2,8 \pm 3,1$ & $70,2 \pm 12,4$ \\
\hline $2000-4000 \mathrm{TL}$ & $83,9 \pm 17,8$ & $24,1 \pm 6,4$ & $2,8 \pm 2,5$ & $69,2 \pm 12,1$ \\
\hline $4000-6000 \mathrm{TL}$ & $85,5 \pm 16,1$ & $24,3 \pm 5,7$ & $3,2 \pm 2,7$ & $70,7 \pm 10,9$ \\
\hline 6000 TL ve üzeri & $85,4 \pm 14,4$ & $24,9 \pm 5,2$ & $2,5 \pm 2,6$ & $70,7 \pm 12,2$ \\
\hline 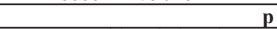 & 0,945 & 0,824 & 0,120 & 0,841 \\
\hline \multicolumn{5}{|l|}{$\begin{array}{l}\text { Ebeveynleri ile birliktelik } \\
\text { durumu }\end{array}$} \\
\hline Anne-baba birlikte & $85,4 \pm 15,6$ & $24,7 \pm 5,6$ & $2,7 \pm 2,6$ & $70,3 \pm 11,8$ \\
\hline Anne-baba ayrı/ölmüss & $80,1 \pm 17,5$ & $22,9 \pm 6,7$ & $3,8 \pm 3,1$ & $69,8 \pm 10,7$ \\
\hline$p$ & 0,155 & 0,201 & 0,071 & 0,551 \\
\hline \multicolumn{5}{|l|}{ İçinde büyüdüğg̈ aile yapısı } \\
\hline Çekirdek aile & $84,7 \pm 16,1$ & $24,5 \pm 5,6$ & $2,8 \pm 2,7$ & $70,3 \pm 11,7$ \\
\hline Geniș aile & $87,2 \pm 13,2$ & $24,7 \pm 6,1$ & $2,5 \pm 2,4$ & $69,9 \pm 12,4$ \\
\hline - & 0,315 & 0,591 & 0,609 & 0,915 \\
\hline \multicolumn{5}{|l|}{ Anne eğitim durumu } \\
\hline Lise ve altı eğitim & $84,6 \pm 16,1$ & $24,1 \pm 5,8$ & $2,7 \pm 2,5$ & $68,5 \pm 12,2$ \\
\hline Lise üstï eğitim & $85,5 \pm 15,5$ & $24,9 \pm 5,5$ & $2,8 \pm 2,7$ & $71,8 \pm 11,1$ \\
\hline 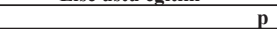 & 0,583 & 0,155 & 0,945 & 0,013 \\
\hline \multicolumn{5}{|l|}{ Baba eğitim durumu } \\
\hline Lise ve altı eğitim & $87,3 \pm 15,8$ & $24,6 \pm 6,1$ & $2,4 \pm 2,4$ & $70,7 \pm 11,1$ \\
\hline Lise üstü eğitim & $84,1 \pm 15,7$ & $24,5 \pm 5,4$ & $2,9 \pm 2,7$ & $70,1 \pm 12,1$ \\
\hline thes & 0,048 & 0,649 & 0,088 & 0,823 \\
\hline \multicolumn{5}{|l|}{ Okuduğu okul } \\
\hline Özel okul & $86,2 \pm 15,2$ & $25,5 \pm 5,4$ & $2,5 \pm 2,3$ & $70,4 \pm 11,4$ \\
\hline Devlet okulu & $83,3 \pm 16,4$ & $22,9 \pm 5,6$ & $3,2 \pm 2,9$ & $70,1 \pm 12,3$ \\
\hline - & 0,092 & 0,000 & 0,033 & 0,844 \\
\hline \multicolumn{5}{|l|}{ Okul bașarısı algısı } \\
\hline Bașarilı & $87,9 \pm 14,2$ & $25,5 \pm 5,2$ & $2,4 \pm 2,5$ & $71,1 \pm 11,2$ \\
\hline Başarısız & $76,2 \pm 16,9$ & $21,7 \pm 5,9$ & $3,8 \pm 2,8$ & $67,7 \pm 12,9$ \\
\hline$p$ & 0,000 & 0,000 & 0,000 & 0,008 \\
\hline \multicolumn{5}{|l|}{ Spor yapma durumu } \\
\hline Yapiyor & $87,2 \pm 15,8$ & $25,4 \pm 5,6$ & $2,4 \pm 2,5$ & $70,9 \pm 11,6$ \\
\hline Yapmiyor & $83,9 \pm 15,6$ & $24,1 \pm 5,6$ & $3,0 \pm 2,7$ & $69,9 \pm 11,8$ \\
\hline 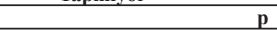 & 0,038 & 0,052 & 0,035 & 0,473 \\
\hline \multicolumn{5}{|l|}{ Arkadaş sayısı } \\
\hline 14 ve altında & $84,2 \pm 17,2$ & $24,2 \pm 6,0$ & $2,8 \pm 2,6$ & $68,9 \pm 12,5$ \\
\hline 14 'ün üstünde & $85,5 \pm 15,4$ & $24,8 \pm 5,5$ & $2,7 \pm 2,7$ & $71,3 \pm 11,4$ \\
\hline - & 0,611 & 0,419 & 0,596 & 0,097 \\
\hline \multicolumn{5}{|l|}{ Yakın arkadaş (kanka) sayısı } \\
\hline 3 ve altinda & $84,8 \pm 16,1$ & $24,2 \pm 5,8$ & $2,9 \pm 2,8$ & $70,1 \pm 11,9$ \\
\hline 3'ün üstünde & $85,7 \pm 15,2$ & $25,1 \pm 5,3$ & $2,7 \pm 2,5$ & $70,9 \pm 11,4$ \\
\hline 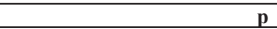 & 0,688 & 0,278 & 0,798 & 0,714 \\
\hline \multicolumn{5}{|l|}{ Arkadaşla geçirdiği süre } \\
\hline 4 saat ve altı & $84,1 \pm 16,6$ & $24,5 \pm 5,7$ & $2,9 \pm 2,7$ & $68,5 \pm 11,4$ \\
\hline 4 saat üstü & $84,7 \pm 16,1$ & $24,1 \pm 6,1$ & $3,0 \pm 2,6$ & $71,5 \pm 12,1$ \\
\hline 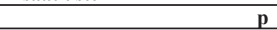 & 0,802 & 0,783 & 0,494 & 0,026 \\
\hline
\end{tabular}

EPOCH ölçeğinin alt boyutları ile demografik özelliklerin ilişkisine bakıldığında kız ergenlerin erkek ergenlere göre ‘ilişkililik’ faktör puanı $(p=0,020)$ daha yüksekti. Kendisini başarılı olarak tanımlayanların 'ilişkililik, mutluluk, iyimserlik, kararlılık' boyutları puanları $(\mathrm{p}=0,001)$ ve 'hayata bağl1l1k' boyutu puanı $(\mathrm{p}=0,003)$ kendisini başarısız olarak tanımlayan ergenlerden daha yüksek saptandı. Özel okulda okuyan ergenlerin EPOCH ölçeği 'mutluluk' boyutu puanı devlet okulunda okuyan ergenlere göre daha yüksek tespit edildi $(p=0,002)$. Spor yapan ergenlerin EPOCH ölçeğinin 'iyimserlik' boyutu puanı spor yapmayanlara göre yüksekti $(p=0,021)$. Yakın arkadaş sayısı ve toplam arkadaş sayısı fazla olan ergenlerde EPOCH ölçeğinin 'ilişkililik' boyutu puanı daha yüksek bulundu. (sırasıyla $\mathrm{p}=0,007$ ve $\mathrm{p}=0,048$ ). DİEÖ ölçeğinin 'olumlu duygu ifadesi' boyutu puanı kız ergenlerde erkeklere göre $(p=0,001)$ daha yüksek bulundu. Ayrıca kendisini başarılı olarak tanımlayan ergenlerin DİEÖ 'yakınlık duygu ifadesi' boyutu puanı $(\mathrm{p}=0,001)$ kendisini başarısız olarak tanımlayan ergenlerden daha yüksekti. Tablo 3 EPOCH ve DİEÖ ölçeklerinin alt boyutları puanlarının demografik özelliklere göre karşılaştırmasını sunmaktadır.

EPOCH, OMÖ-KF, SMBÖ, DİEÖ parametrelerinin korelasyonları yapıldı (Tablo 4). EPOCH ile DİEÖ arasında pozitif yönde orta düzeyde korelasyon tespit edildi $(\mathrm{r}=0,349, \mathrm{p}=0,001)$. Daha sonra bunlardan korelasyonları önemli olanlar arasında lineer regresyon analizi yapıldı. Doğrusal regresyon analizinde toplam OMÖ-KF'daki yüksekliğin $\% 48,7$ 'sinin $\left(\mathrm{R}^{2}=0,487\right)$ ve toplam DİEÖ puanındaki yüksekliğin \%12,2'sinin $\left(\mathrm{R}^{2}=0,122\right) \mathrm{EPOCH}$ puanına atfedilebileceği saptand1 (Grafik 1 ve 2). 
Tablo 3. EPOCH ve DİE ölçek alt boyutları puanlarının demografik özelliklere göre karşılaştırılması

\begin{tabular}{|c|c|c|c|c|c|c|c|c|}
\hline & $\begin{array}{l}\text { EPOCH } \\
\text { Bağlluk } \\
\end{array}$ & $\begin{array}{c}\text { EPOCH } \\
\text { Kararlulık } \\
\end{array}$ & $\begin{array}{l}\text { EPOCH } \\
\text { İyimserlik } \\
\end{array}$ & $\begin{array}{l}\text { EPOCH } \\
\text { İlişkililik } \\
\end{array}$ & $\begin{array}{c}\text { EPOCH } \\
\text { Mutluluk } \\
\end{array}$ & $\begin{array}{c}\text { DIEÖ } \\
\text { Olumlu } \\
\end{array}$ & $\begin{array}{c}\text { DİEÖ } \\
\text { Yakınlık } \\
\end{array}$ & $\begin{array}{c}\text { DiEÖ } \\
\text { Olumsuz } \\
\end{array}$ \\
\hline \multicolumn{9}{|l|}{ Cinsiyet } \\
\hline Kadın & $24,9 \pm 6,2$ & $13,6 \pm 3,5$ & $14,2 \pm 4,1$ & $17,4 \pm 3,1$ & $15,1 \pm 3,7$ & $29,2 \pm 6,1$ & $24,1 \pm 4,2$ & $18,8 \pm 4,1$ \\
\hline Erkek & $25,2 \pm 5,6$ & $12,9 \pm 3,3$ & $14,4 \pm 3,7$ & $17,1 \pm 2,7$ & $15,0 \pm 4,0$ & $26,6 \pm 6,4$ & $23,5 \pm 4,7$ & $18,1 \pm 4,3$ \\
\hline $\mathbf{p}$ & 0,694 & 0,072 & 0,724 & 0,020 & 0,938 & 0,000 & 0,267 & 0,079 \\
\hline \multicolumn{9}{|l|}{ Aile gelir durumu } \\
\hline $0-2000 \mathrm{TL}$ & $25,6 \pm 5,7$ & $14,1 \pm 4,2$ & $14,7 \pm 3,9$ & $16,7 \pm 3,6$ & $14,4 \pm 4,5$ & $27,8 \pm 7,0$ & $23,9 \pm 4,1$ & $18,4 \pm 4,1$ \\
\hline $4000-6000 \mathrm{TL}$ & $25,1 \pm 5,9$ & $13,1 \pm 3,5$ & $14,5 \pm 4,2$ & $17,5 \pm 2,6$ & $15,3 \pm 3,8$ & $28,5 \pm 5,8$ & $23,7 \pm 4,2$ & $18,5 \pm 4,3$ \\
\hline 6000 TL ve üzeri & $25,1 \pm 5,6$ & $13,3 \pm 3,3$ & $14,3 \pm 3,5$ & $17,4 \pm 2,8$ & $15,2 \pm 3,6$ & $27,9 \pm 6,6$ & $24,2 \pm 4,6$ & $18,6 \pm 4,3$ \\
\hline $\mathbf{p}$ & 0,919 & 0,907 & 0,572 & 0,870 & 0,469 & 0,365 & 0,352 & 0,725 \\
\hline \multicolumn{9}{|c|}{ Ebeveynleri ile birliktelik durumu } \\
\hline Anne-baba birlikte & $25,1 \pm 5,9$ & $13,3 \pm 3,5$ & $14,5 \pm 3,8$ & $17,3 \pm 2,9$ & $15,2 \pm 3,8$ & $28,0 \pm 6,4$ & $23,8 \pm 4,5$ & $18,5 \pm 4,2$ \\
\hline $\mathbf{p}$ & 0,601 & 0,614 & 0,118 & 0,051 & 0,073 & 0,495 & 0,928 & 0,793 \\
\hline \multicolumn{9}{|c|}{ İ́çinde büyüdüğü aile yapısı } \\
\hline Çekirdek aile & $24,9 \pm 6,0$ & $13,2 \pm 3,5$ & $14,2 \pm 3,9$ & $17,2 \pm 2,9$ & $14,9 \pm 3,9$ & $28,0 \pm 6,2$ & $23,9 \pm 4,4$ & $18,4 \pm 4,2$ \\
\hline Geniș aile & $25,7 \pm 5,6$ & $13,5 \pm 3,3$ & $14,9 \pm 3,5$ & $17,4 \pm 2,4$ & $15,4 \pm 3,6$ & $27,4 \pm 7,4$ & $23,3 \pm 4,5$ & $19,0 \pm 4,2$ \\
\hline $\mathbf{p}$ & 0,378 & 0,402 & 0,299 & 0,921 & 0,458 & 0,854 & 0,279 & 0,419 \\
\hline \multicolumn{9}{|l|}{ Anne eğitim durumu } \\
\hline Lise ve altı eğitim & $25,2 \pm 6,0$ & $13,4 \pm 3,6$ & $14,2 \pm 3,9$ & $17,0 \pm 3,0$ & $14,6 \pm 4,0$ & $27,2 \pm 6,7$ & $22,9 \pm 4,3$ & $18,4 \pm 4,3$ \\
\hline Lise üstü eğitim & $24,9 \pm 5,9$ & $13,2 \pm 3,4$ & $14,4 \pm 3,9$ & $17,5 \pm 2,8$ & $15,4 \pm 3,7$ & $28,7 \pm 6,0$ & $24,6 \pm 4,4$ & $18,5 \pm 4,2$ \\
\hline $\mathbf{p}$ & 0,607 & 0,801 & 0,657 & 0,108 & 0,066 & 0,039 & 0,001 & 0,879 \\
\hline $\begin{array}{l}\text { Baba eğitim } \\
\text { durumu }\end{array}$ & & & & & & & & \\
\hline Lise üstü eğitim & $24,6 \pm 5,8$ & $12,9 \pm 3,4$ & $14,2 \pm 3,9$ & $17,2 \pm 2,8$ & $15,0 \pm 3,8$ & $27,8 \pm 6,4$ & $23,7 \pm 4,5$ & $18,6 \pm 4,4$ \\
\hline p & 0,007 & 0,006 & 0,272 & 0,647 & 0,511 & 0,656 & 0,350 & 0,466 \\
\hline \multicolumn{9}{|l|}{ Okuduğu okul } \\
\hline Özel okul & $25,07 \pm 5,8$ & $13,4 \pm 3,4$ & $14,6 \pm 3,7$ & $17,4 \pm 2,7$ & $15,6 \pm 3,5$ & $27,9 \pm 6,1$ & $23,8 \pm 4,3$ & $18,5 \pm 4,3$ \\
\hline Devlet okulu & $25,09 \pm 6,0$ & $13,1 \pm 3,5$ & $13,9 \pm 4,0$ & $16,9 \pm 3,1$ & $14,2 \pm 4,1$ & $28,0 \pm 6,9$ & $23,7 \pm 4,5$ & $18,3 \pm 4,1$ \\
\hline $\mathbf{p}$ & 0,942 & 0,477 & 0,065 & 0,307 & 0,002 & 0,532 & 0,890 & 0,707 \\
\hline \multicolumn{9}{|l|}{ Okul bașarısı algııı } \\
\hline Başarlı & $25,6 \pm 5,7$ & $13,9 \pm 3,3$ & $15,0 \pm 3,7$ & $17,8 \pm 2,4$ & $15,6 \pm 3,5$ & $28,2 \pm 6,2$ & $24,3 \pm 4,2$ & $18,6 \pm 4,2$ \\
\hline Başarıssz & $23,4 \pm 6,2$ & $11,4 \pm 3,3$ & $12,4 \pm 3,9$ & $15,7 \pm 3,6$ & $13,2 \pm 4,3$ & $27,2 \pm 6,7$ & $22,3 \pm 4,8$ & $18,1 \pm 4,3$ \\
\hline p & 0,003 & 0,000 & 0,000 & 0,000 & 0,000 & 0,088 & 0,001 & 0,337 \\
\hline \multicolumn{9}{|l|}{ Spor yapma durumu } \\
\hline Yapiyor & $25,4 \pm 6,4$ & $13,8 \pm 3,4$ & $14,9 \pm 3,8$ & $17,6 \pm 2,7$ & $15,5 \pm 3,7$ & $28,2 \pm 6,2$ & $24,2 \pm 4,7$ & $18,4 \pm 4,5$ \\
\hline Yapmıyor & $24,9 \pm 5,7$ & $13,0 \pm 3,5$ & $14,0 \pm 3,9$ & $17,1 \pm 2,9$ & $14,8 \pm 3,9$ & $27,8 \pm 6,5$ & $23,6 \pm 4,3$ & $18,5 \pm 4,1$ \\
\hline $\mathbf{p}$ & 0,307 & 0,053 & 0,021 & 0,101 & 0,141 & 0,652 & 0,090 & 0,949 \\
\hline \multicolumn{9}{|l|}{ Arkadaş sayısı } \\
\hline 14 ve altında & $25,1 \pm 6,1$ & $13,2 \pm 3,7$ & $14,1 \pm 4,0$ & $16,8 \pm 3,2$ & $14,9 \pm 4,1$ & $27,6 \pm 6,8$ & $23,2 \pm 4,1$ & $18,2 \pm 4,5$ \\
\hline 14 'ün üstünde & $24,6 \pm 6,0$ & $13,4 \pm 3,4$ & $14,6 \pm 3,8$ & $17,6 \pm 2,5$ & $15,2 \pm 3,8$ & $28,2 \pm 6,3$ & $24,3 \pm 4,5$ & $18,7 \pm 4,0$ \\
\hline $\mathbf{p}$ & 0,442 & 0,688 & 0,361 & 0,048 & 0,747 & 0,421 & 0,024 & 0,506 \\
\hline \multicolumn{9}{|c|}{ Yakın arkadas (kanka) sayııı } \\
\hline 3 ve altında & $25,4 \pm 5,8$ & $13,4 \pm 3,5$ & $14,3 \pm 4,0$ & $16,9 \pm 3,0$ & $14,8 \pm 3,8$ & $28,3 \pm 6,3$ & $23,7 \pm 4,5$ & $18,2 \pm 4,3$ \\
\hline 3'ün üstünde & $24,6 \pm 5,9$ & $13,3 \pm 3,4$ & $14,5 \pm 3,8$ & $17,8 \pm 2,4$ & $15,3 \pm 4,0$ & $27,9 \pm 6,3$ & $24,0 \pm 4,3$ & $18,9 \pm 4,1$ \\
\hline $\mathbf{p}$ & 0,161 & 0,925 & 0,537 & 0,007 & 0,085 & 0,523 & 0,595 & 0,113 \\
\hline \multicolumn{9}{|c|}{ Arkadașla geçirdiği süre } \\
\hline 4 saat ve altı & $24,3 \pm 5,9$ & $12,8 \pm 3,5$ & $14,0 \pm 4,1$ & $17,4 \pm 2,9$ & $14,8 \pm 4,0$ & $28,6 \pm 6,4$ & $23,9 \pm 4,1$ & $18,8 \pm 4,1$ \\
\hline 4 saat üstü & $25,4 \pm 5,9$ & $13,6 \pm 3,5$ & $14,4 \pm 3,9$ & $17,0 \pm 2,9$ & $14,9 \pm 4,1$ & $26,9 \pm 6,6$ & $23,4 \pm 4,5$ & $17,9 \pm 4,3$ \\
\hline $\mathrm{p}$ & 0,125 & 0,038 & 0,306 & 0,097 & 0,867 & 0,042 & 0,218 & 0,107 \\
\hline
\end{tabular}


Tablo 4. EPOCH, OMÖ-KF, SMBÖ, DİEÖ parametrelerinin

korelasyon tablosu

\begin{tabular}{|c|c|c|c|c|c|}
\hline Parametreler & & ЕPOCH & OMÖ-KF & SMBÖ & DİEÖ \\
\hline \multirow[b]{2}{*}{ EPOCH } & $\mathrm{r}$ & \multirow{2}{*}{1} & & & \\
\hline & $\mathrm{p}$ & & & & \\
\hline \multirow[b]{2}{*}{ OMÖ-KF } & $\mathrm{r}$ & $0,698^{* *}$ & \multirow[t]{2}{*}{1} & & \\
\hline & $\mathrm{p}$ & 0,000 & & & \\
\hline \multirow[b]{2}{*}{ SMBÖ } & $\mathrm{r}$ & $-0,199 * *$ & $-0,260^{* *}$ & \multirow{2}{*}{1} & \\
\hline & $\mathrm{p}$ & 0,000 & 0,000 & & \\
\hline DIEO & $\begin{array}{l}\mathrm{r} \\
\mathrm{p}\end{array}$ & $\begin{array}{l}0,349^{* *} \\
0,000\end{array}$ & $\begin{array}{l}0,279 \\
0,000\end{array}$ & $\begin{array}{l}-0,010 \\
0,840\end{array}$ & 1 \\
\hline
\end{tabular}

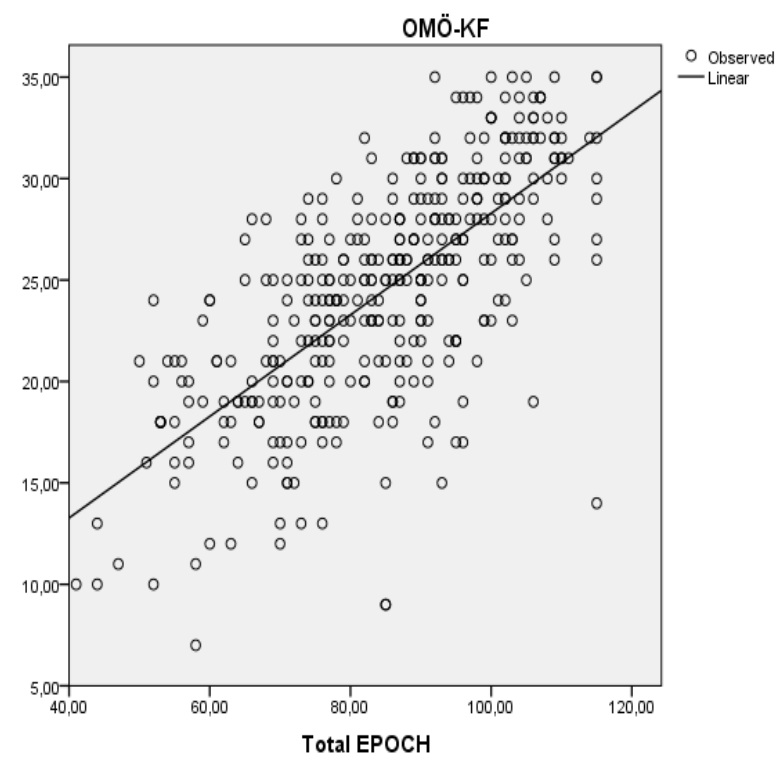

Grafik 1. EPOCH ile OMÖ-KF arasındaki lineer regresyon analizi $\mathrm{R}^{2}=0,487 \quad \mathrm{p}<0,001$

DiEÖ

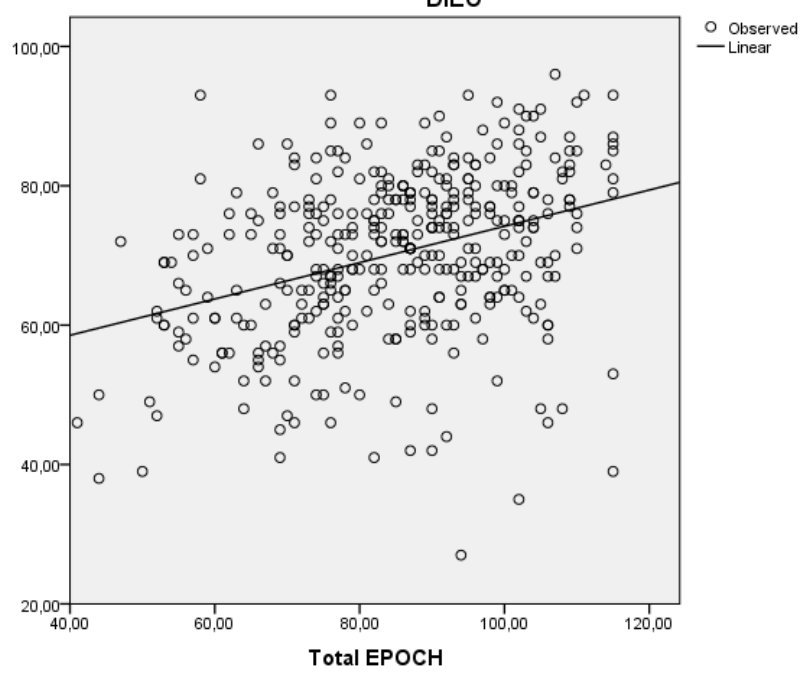

Grafik 2. EPOCH ile DİEÖ arasındaki lineer regresyon analizi $\mathrm{R}^{2}=0,122 \quad \mathrm{p}<0,001$

\section{Tartışma}

$\mathrm{Bu}$ çalışma; insan hayatında oldukça önemli bir süreç olan ergenlik dönemindeki iyilik hali, mutlu olma, kendini ifade etme ve sosyal medya bağımlılığını değerlendirmesi, ayrıca çeşitli çevresel faktörlerin bu maddelerle ilişkisini ortaya koyması ve çıkan sonuçlara göre ergenlerin kendini geliştirebilecekleri yönlerin belirlenebilmesi açısından oldukça önemlidir. Çünkü ergenleri bu çalışmada olduğu gibi çok yönlü inceleyen çalışma sayısı azdır ve önceki yapılan çalışmalarda daha çok olumsuz duygulardan yola çıkılmış, ergenlerden ziyade yetişkinler üzerinden çalışılmıştır. Toplum nüfusunun belki de en önemli kısmını oluşturan ergenlerin iyi oluşu, iyilik halleri ile ilgili araştırmalar sayesinde geleceğin erişkinlerinin iyi olması sağlanabilir (1).

Cinsiyet açısından EPOCH, OMÖ-KF ve SMBÖ-KF puanları arasında fark olmaması teknolojinin erkek egemen olduğunu ifade eden yayınların aksine kızların da benzer teknoloji kullanımı olduğunu düşündürebilir $(26,27)$. Sadece kendini ifade etme puanlarının kızlar açısından yüksek olması yayınlarda da belirtilen empati, iletişim becerileri açısından kızların daha doğuştan gelen özelliğine atfedilebilir (28). Ebeveyn eğitimi sadece lise üstü eğitimli annelerin çocuklarında kendini ifade edebilme puanının daha yüksek olması ile ortaya çıkmıştır. Bu da eğitimli annelerin bu yaş grubu çocuklarına anlamaya ve yardımcı olmaya daha eğimli olduğunu düşündürebilir. Baba eğitimi ise $\mathrm{EPOCH}$ puanı alt ölçeklerinde bağl1lık ve kararlılık puanlarında lise ve altı eğitimli babaya sahip ergenlerin hayat sorumluluğunu babalarından çok kendi üzerlerinde hissettiklerini düşündürebilir. Özel okulda okuyan öğrencilerin devlet okulunda okuyanlara göre daha mutlu olması ve daha az sosyal medya bağımlısı olması dikkat çekicidir. Bu durumun oluşmasında özel okullarda öğrencinin cep telefonu veya bilgisayar gibi araçları belli sınırlar içerisinde kullanılması olabilir. Ayrıca özel okul eğitim programları içinde spor ve sosyal aktivite ile ilgili etkinliklerin daha çok yer alıyor olması da etkili olabilir. Çünkü internete girecek araçlarla fazla zamansal temas ve sosyal aktivite azlığının sosyal medya bağımlığında etkisi olduğunu gösteren çeşitli yayınlar vardır (29).

Bu çalışmadaki EPOCH boyutlarına bakıldığında öncelikle kendini başarılı görenlerin tüm boyutlarda puanlarının yüksek olması ve mutluluk dışında bu durumun okudukları okuldan ve diğer demografik özelliklerden bağımsız olması önemli bir bulgudur (30). Başar1; olumlu bir duygu ve olumlu bir deneyim olarak tüm diğer olumlu psikolojik donanımlar gibi kişiyi mutlu, kararlı, doygun ve iyimser kılma potansiyeline sahiptir (10). Buradaki sonuç da bunu destekler niteliktedir. Spor yapan ergenlerin iyimserlik puanının daha yüksek olması ve sporun endorfin salınımındaki etkisine bağlanabilir (30-32). Böylelikle ergenler anksiyete ve stres durumuyla daha kolay baş edebilirler.

Çalışmadaki ilginç sonuçlardan biri de arkadaş ve kanka sayısı fazla olan ergenlerin ilişkililik puanının yüksek olmasıdır. Bunun anlamı bu ergenlerin ilişkilerinden memnun olması, arkadaşlarının değer verdiğini düşünmesi anlamı taşır ki arkadaşlık ilişkilerinin ergenlikteki önemi bilinmektedir (2,3,20). İlaveten kızlarda ilişkililik puanının erkeklere göre daha yüksek olması sosyal ilişki ağlarının daha geniş olmasıyla bağlantılı olabilir.

Duygular sözel ya da mimik, el-kol hareketleri gibi sözel olmayan 
yollarla ifade edilir. Kişinin duygularının farkında olması ve istediğ gibi ifade edebilmesi sağlıklı ilişkiler kurabilmesi, kendisiyle barışık olması için önemlidir. Duyguların düzenlenip ifade edilmesinde sosyokültürel ortam, aile yapısı ve akranların etkisi olduğu söylenmektedir

$(8,20)$. Ergenlikte tisunami etkisiyle yaşanan dönüşüm bazı ergenlerin içe kapanmasına ve kendini ifade edememesine ya da ifade edemediğini düşünmesine yol açabilir $(8,20)$. Sunulan çalışmada kız öğrencilerin erkek öğrencilere göre kendisini daha iyi ifade ettiği, kendini başarılı görenlerin kendini ifade etme gücünün yüksek olduğu görülmüştür. İlaveten, kendisini iyi ifade edebilen ergenlerin daha mutlu olduğu tespit edilmiştir. Kendini başarılı görenlerin özgüvenle kendilerini daha iyi ifade edebilmesi bu farkın oluşmasına yol açmış olabilir (22). Son 20 yılda duyguları iyi ifade etmenin iyi oluşla ilişkisini araştıran birçok araştırma yapılmıştır. Bu çalışmalarda duyguların iyi bir şekilde ifade edilmesi akıl ve beden sağlığının önemli bir göstergesi olarak görülmektedir $(8,22,23)$. Kendini ifade edemeyen ergenler yetişkinlik dönemlerinde de birçok sorunla karşılaşabilir (1517). İlaveten, annesi lise üstü eğitimli olan öğrencilerin olumlu duygu ve yakınlık duygu ifadesi yüksek bulunması eğitim düzeyi arttıça annenin çocuğuna kendini ifade etme şansı vermesi ile açıklanabilir (8).

Gitgide yaygınlaşan teknoloji ile birlikte sosyal medya herkesin hayatının içine girmiş durumdadır. Ergenler arasında sosyal medya yaygin olarak kullanılmakta, kendilerini ifade etme yeri olarak görülmektedir (18, 29, 33,34). San Francisco' da 2009 senesinde yapılan bir araştırmada ergenlerin \% 51'inin sosyal paylaşım sitelerini günde bir defadan fazla kontrol ettiğini ve \% 22 'sinin sosyal ağ sitelerini günde 10 kereden fazla kontrol ettiğini göstermektedir. Ergenlerin bu kadar fazla oranda sosyal medya ile iç içe olması doğal olarak birçok sorunu beraberinde getirmektedir (35). Ergenlerde sosyal medya kullanmanın sosyalleşme, okul derslerine yardımcı olma, sağlıkla ilgili konulara kolayca erișebilme gibi olumlu yönleri olduğu gibi sanal zorbalık, online taciz, gizlilik endişesi, facebook depresyonu, internet bağımlılığı gibi olumsuz yönleri üzerinde de özellikle durulmaktadır $(8,18,19,33,34)$. Sunulan çalışmada OMÖKF ile SMBÖ-KF arasında negatif yönde ilişki saptanması ergenlerin sosyal medya bağımlılığı arttıkça mutsuzlaştıklarını göstermektedir. Literatürdeki çalışmalar da mutluluk düzeyi azaldıkça sosyal medya bağımlılığının arttığını göstermektedir $(18,19,33)$. Devlet okulunda okuyan öğrencilerin daha mutsuz olması ve sosyal medya bağımlılığının daha yüksek olması üzücü bir sonuçtur ve devlet kurumlarındaki eğiticilere ve bu öğrencilerin ailelerine özel sorumluluklar yüklemektedir. Kendini başarısız bulma ile sosyal medya bağımlılı̆̆ arasındaki bağ da uyarıcı bir bulgudur.

Sonuç olarak bu çalışmada özel okulda okuyan ergenlerin devlet okulunda okuyanlara göre daha mutlu ve daha az sosyal medya bağımlısı olduğu, kendini başarılı görenlerin kendini daha iyi ifade ettiği, daha mutlu ve daha iyi olduğu bulunmuştur. Ayrıca kendini başarısız görenlerde, devlet okullarında okuyanlarda ve spor yapmayanlarda sosyal medya bağımlılı̆̆ının daha yüksek olması dikkat çekici sonuçlardır. Son yıllarda ergenlerin kendilerini iyi hissetmesi ve bu iyi olma halini etkileyen durumları ortaya çıkarmaya yönelik çalışmalar tüm dünyada artmaktadır (36). Çünkü bunları belirlemek ergenlerin sağlıklı gelişimleri için yapılacak girişimlerde önemlidir. Olumlu kişilik özelliklerinin gelişimi, kendilerini ifade etmelerinin sağlanması, iyi olmayı tetikleyen etkinliklerin artırılması ark ergenlerin gelecekte de kendilerini iyi hissetmelerini veya iyi olmaya çalışmalarını sağlayacaktır (37). Bu sonuçlar ergenlik döneminde sosyal teşviklerin, spora yönlendirmenin ve genel iyi oluşlarını artırabilmek için psikolojik ve ekonomik desteklerin önemini ortaya koymaktadır düşüncesindeyiz.

\section{Kaynaklar}

1-Demirci İ, Ekși F. Ergenler için beș boyutlu iyi oluş modeli: EPOCH Ölçeği'nin Türkçe formunun geçerliği ve güvenirliği. Gençlik Araştırmaları Dergisi 2015; 3(3): 9-30.

2-Kern ML, Benson L, Steinberg EA, Steinberg L. The EPOCH Measure of adolescent well-being. Psychological Assessment 2016; 28( 5): 586-97.

3-Kern ML, Waters LE, Adler A, White AV. A multidimensional approach to measuring well-being in students: Application of the PERMA framework. J Posit Psychol 2015; 10(3): 262-71.

4-Hills P, Argyle M. The Oxford Happiness Questionnaire: a compact scale for the measurement of psychological well-being. Pers Individ Dif 2002; 33: 1073-82.

5-Rusk RD, Waters L. A psycho-social system approach to well-being: empirically deriving the five domains of positive functioning. J Posit Psychol 2015; 10(2): 141-52.

6-Ryff CD. Happiness is everything, or is it? Explorations on the meaning of psychological well-being. J Pers Soc Psychol 1989; 57(6): 1069-81.

\section{7-Keyes CLM. Social well-being. Soc Psychol Q 1998; 61(2): 121-40.}

8-Kuyumcu B, Güven M. Türk ve İngiliz üniversite öğrencilerinin duygularını fark etmeleri ve ifade etmeleri ile psikolojik iyi oluşları arasındaki ilişki. GEFAD/GUJGEF 2012; 32(3): 589-607.

9-Huppert FA, Timothy TC. Flourishing across europe: application of a new conceptual framework for defining well-being. Soc Indic Res 2013; 110: 837-61.

10-Seligman ME, Csikszentmihalyi M. Positive psychology. An introduction. Am Psychol 2000; 55(1): 5-14.

11- Bryant G, Heard H, Watson J. The National Mental Health, Dementia and Neurology Intelligence Network; lead authors. measuring mental wellbeing in children and young people. 2015; PHE publications gateway number: 2015325

12- Rose $\mathrm{T}$, Joe $\mathrm{S}$, Williams A, et al. measuring mental wellbeing among adolescents: a systematic review of instruments. J Child Fam Stud 2017; 1-13.

13-Public Health England (2014) Improving Young People's Health and Wellbeing: A Framework for Public Health. Available at: www.gov.uk/government/uploads/system uploads/attachment_data/file/399391/20150128_YP_HW_Framework_FINAL_ WP 3_.pdf (erişim tarihi 10 Mayıs 2020)

14-Laube C, van den Bos W. Hormones and affect in adolescent decision making S. Kim, J. Reeve, M. Bong (Eds.), Recent Developments in Neuroscience Research on Human Motivation (Advances in Motivation and Achievement, Volume 19), Emerald Group Publishing Limited, UK (2016), pp. 259-281.

15-Greydanus DE, Shek D. Deliberate self-harm and suicide in adolescents. Keio J Med 2009; 58 (3): 144-51.

16-McKinnon B, Gariépy G, Sentenac M, Elga FJ. Adolescent suicidal behaviours in 32 low- and middle-income countries. Bull World Health Organ 2016; 94: 340-50F. 17- Eskin M. Ergen ruh sağlık sorunları ve intihar davranıșlarıyla ilișkileri. Klinik psikiyatri 2000; 3: 228-34.

18-Doğan U, Karakuș Y. Lise öğrencilerinin sosyal ağ siteleri kullanımının yordayıcısı olarak çok boyutlu yalnızlık. Sakarya University Journal of Education 2016; 6(1): 57-71.

19- O'Keeffe GS, Clarke-Pearson K. Council on communications and mediaaapAmerican Academy of Pediatrics. Clinical report- the impact of social media on children, adolescents, and families. Pediatrics 2011;127:800-4

20-Avcı M. Ergenlikte toplumsal uyum sorunları. Sosyal Bilimler Enstitüsü Dergisi 2006; 7 (1): 39-63.

21-King LA, Emmons RA. Conflict over emotional expression: psychological and 
physical correlates. J Pers Soc Psychol 1990; 58(5): 864-77.

22-Kuzucu Y. Duyguları ifade etme ölçeği'nin uyarlanması: geçerlik ve güvenirlik çalışmaları Kastamonu Eğitim Dergisi 2011; 19(3) 779-92.

23-Doğan T, Çötok NA. Oxford Mutluluk Ölçeği kısa formunun Türkçe uyarlaması: geçerlik ve güvenirlik çalışması. Türk Psikolojik Danışma ve Rehberlik Dergisi 2011, 4 (36), 165-72.

24-van den Eijnden RJJM, Lemmens JS, Valkenburg PM. The social media disorder scale. Computers in Human Behavior 2016; 61: $478 \mathrm{e} 487$

25-Taş İ. Ergenler İçin Sosyal Medya Bağımlılığı Ölçeği kısa formunun (SMBÖ$\mathrm{KF})$ geçerlik ve güvenirlik çalışması. Online Journal of Technology Addiction \& Cyberbullying 2017; 4(1): 27-40.

26-Bimber B. Measuring the gender gap on the internet. Soc Sci Q 2000; 81(3): 868-76.

27-Durndella A, Haag Z. Computer self efficacy, computer anxiety,attitudes towards the Internet and reported experience with the Internet, by gender, in an East European sample. Computers in Human Behavior 2002; 18: 521-35.

28-Karaoglu N, Pekcan S, Yilmaz S. Are problem based scenarios supporting the positive affect and empathy of medical students? Procedia Social and Behavioral Sciences 2013; 82: 101-7.

29-Derin S, Bilge F. Ergenlerde internet bağımlılığ ve öznel iyi oluş düzeyi. Türk Psikolojik Danışma ve Rehberlik Dergisi 2016; 6(46): 35-51.

30-Özgün A, Yaşartürk F, Ayhan B, Bozkuş T. Hentbolcuların spora özgü başarı motivasyonu ve mutluluk düzeyleri arasındaki ilişkinin incelenmesi. International Journal of Cultural and Social Studies (IntJCSS) 2017; 3 (SI): 83-94.

31-Harber VJ, Sutton JR. Endorphins and exercise. Sports Medicine 1984; 1: 154-71.

32-Yalçın U, Balcı V. 7-14 yaş arası çocuklarda spora katılımdan sonra okul başarılarında, fiziksel ve sosyal davranışlarında olușan değișimlerin incelenmesi. SPORMETRE Beden Eğitimi ve Spor Bilimleri Dergisi 2013; XI (1) 27-33.

33-Andreassen CS, Pallesen S, Griffiths MD. The relationship between addictive use of social media, narcissism, and self-esteem: Findings from a large national survey. Addictive Behaviors 2017; 64: 287-93.

34-Primack BA, Shensa A, Escobar-Viera CG, et al. Use of multiple social media platforms and symptoms of depression and anxiety: A nationally-representative study among U.S. young adults. Computers in Human Behavior 2017; 69: 1-9.

35-Common Sense Media. Is technology networking changing childhood? A national poll. San Francisco, CA: Common Sense Media; 2009. Available at: www.commonsensemedia org/sites/default/ files/CSM_teen_social_media_080609_FINAL.pdf. (erişim tarihi 10 Mayis 2020)

36- Zeng G, Peng K, Hu CP. The network structure of adolescent well-being traits: Results from a large-scale Chinese sample. Front Psychol 2019; 10: 2783.

37- Giacomo DD, Ranieri J, Fiasca F, Mattei A. Lifestyle, body mass index and wellnes in youth: Strengthens and weakness in Italian youth. Health Psychol Res 2019; 7(1): 8035. 